\title{
Efficacy of Antilipopolysaccharide and Anti-Tumor Necrosis Factor Monoclonal Antibodies in a Neutropenic Rat Model of Pseudomonas Sepsis
}

\author{
Steven M. Opal,* Alan S. Cross, ${ }^{\ddagger}$ Jerald C. Sadoff, ${ }^{\text {Hugh H. Collins, }{ }^{\ddagger} \text { Naimh M. Kelly, }}$ \\ Gary H. Victor," John E. Palardy," and Mark W. Bodmer \\ *Infectious Disease Division, Memorial Hospital of Rhode Island and Brown University Program in Medicine, Providence, \\ Rhode Island 02912; ${ }^{\ddagger}$ Walter Reed Army Institute of Research, Walter Reed Army Medical Center, \\ Washington, DC 20307-5100; and ${ }^{5}$ Celltech Ltd., Slough SL1 4EN, United Kingdom
}

\begin{abstract}
Monoclonal antibodies (MAb) directed against bacterial lipopolysaccharide (LPS) and tumor necrosis factor-alpha (TNF) provide partial protection in experimental models of septic shock. To determine if additional benefit accrues from a combination of anti-TNF and anti-LPS MAb in the treatment of septic shock, a neutropenic rat model was developed to study active infection with Pseudomonas aeruginosa 12.4.4. Animals were treated intravenously with an irrelevant MAb (group 1); antiTNF MAb (group 2); MAb directed against $P$. aeruginosa 12.4.4 LPS (group 3); or a combination of anti-TNF and antiLPS MAb (group 4). None of the control animals in group 1 survived the $7-d$ period of neutropenia $(0 / 16)$. In contrast, the survival rate was $44 \%$ in group $2(P<0.02) ; 37 \%$ in group $3(P$ $<0.05)$; and $75 \%$ in group $4(P<0.0002)$. The combination of monoclonal antibodies provided greater protection than either MAb given alone $(P<0.05)$. Serum TNF levels during infection were significantly greater in groups 1 and $3(20.1 \pm 3.3 \mathrm{U}$, mean \pm SE) than in groups 2 and $4(0.9 \pm 0.8 \mathrm{U}, P<0.0001)$. These results indicate that a combination of monoclonal antibodies to LPS and TNF have additive benefit in experimental Pseudomonas aeruginosa sepsis. This immunotherapeutic approach may be of potential utility in the management of serious, gram-negative bacterial infection in neutropenic patients. ( $J$. Clin. Invest. 1991. 88:885-890.) Key words: endotoxin • septic shock • Pseudomonas aeruginosa • cytokines • immunotherapy
\end{abstract}

\section{Introduction}

Septic shock continues to be associated with an unacceptably high mortality rate despite the availability of a wide variety of potent antimicrobial agents $(1,2)$. Consequently, other forms of treatment, such as immunotherapy, have been studied to supplement conventional therapy with antibiotics and supportive care. Both standard immune globulin and immunoglobulin that is hyperimmune to specific bacterial surface determinants have been shown to mediate opsonophagocytosis of bacteria in vitro and to offer protection in animal models of infection

This work was presented in part at the 29th Annual Interscience Conference on Antimicrobial Agents and Chemotherapy, 17-20 September 1989, Houston, TX (Abstr. No. 840).

Received for publication 13 March 1990 and in revised form 5 May 1991.

J. Clin. Invest.

(c) The American Society for Clinical Investigation, Inc.

$0021-9738 / 91 / 09 / 0885 / 06 \$ 2.00$

Volume 88, September 1991, 885-890
(3). These products are currently undergoing clinical evaluation (4).

In addition, other strategies for the immunotherapy of septic shock have been suggested. The hemodynamic and pathologic consequences of septic shock caused by gram-negative bacilli are principally triggered by bacterial endotoxin or lipopolysaccharide (LPS). Circulating levels of endotoxin accompany active gram-negative bacteremia and may be transiently elevated after the initiation of antimicrobial therapy, presumably from the lysis of bacteria (5). Circulating endotoxin initiates a cascade of potentially harmful biologic effects. A useful strategy to prevent the deleterious effects of endotoxin might include the provision of passive immunity against bacterial endotoxin itself (6). Therapy with polyclonal and monoclonal antibody directed against widely shared epitopes in the core glycolipid of LPS has been shown to be partially protective in a number of experimental and clinical studies of septic shock $(7,8)$.

Recent evidence indicates that the proinflammatory cytokine tumor necrosis factor-alpha (TNF) is an important mediator of the hemodynamic and pathophysiologic effects of endotoxin $(9,10)$. Polyclonal and monoclonal antibodies directed against TNF protect animals from otherwise lethal doses of endotoxin (11-14) and massive intravenous doses of viable Escherichia coli (15). Anti-TNF monoclonal antibodies have recently been administered to septic patients in a phase I human trial (16).

Utilizing a recently developed neutropenic rat model of active Pseudomonas sepsis, we have demonstrated that antimicrobial agents combined with a monoclonal antibody against the O-side chain of LPS (17) or combined with a monoclonal antibody against TNF (18) provide protection from lethal infection. Because each of these monoclonal antibodies act at a different phase in the development of the septic state, we sought to determine if a combination both monoclonal antibodies would be superior to either monoclonal antibody alone in the protection of neutropenic animals during Pseudomonas sepsis.

\section{Methods}

Animal model. Pathogen-free, female Sprague-Dawley rats (Charles River Breeding Laboratories, Wilmington, MA) weighing between 125 and $175 \mathrm{~g}$ were maintained in filtered, biological safety cages and allowed to eat and drink ad libitum. The details of this animal model have been described previously (17). After premedication of each animal with intramuscular cefamandole (Eli Lilly Co., Inc., Indianapolis, IN) $(100 \mathrm{mg} / \mathrm{kg}$ administered every other day), animals were rendered neutropenic by the administration of cyclophosphamide (BristolMyers, Evansville, IN) intraperitoneally (i.p.) at a dose of $150 \mathrm{mg} / \mathrm{kg}$ 
followed by a second dose of $50 \mathrm{mg} / \mathrm{kg}$ i.p. $72 \mathrm{~h}$ later. An oral challenge with a virulent, human isolate of Pseudomonas aeruginosa ( $P$. aeruginosa 12.4.4, provided by Dr. A. McManus, San Antonio, TX) was given by orogastric feeding tube time 0,48 , and $96 \mathrm{~h}$ after the administration of the first dose of cyclophosphamide. The challenge strain was given at a dose of $\sim 10^{6}$ organisms in $1 \mathrm{ml}$ of PBS. All manipulations of the animals were conducted under light $\mathrm{CO}_{2}$ anesthesia to minimize trauma to the animals. Quantitative blood cultures, complete blood counts, and other serum determinations were obtained $24 \mathrm{~h}$ before the first dose of cyclophosphamide and at 72 and $120 \mathrm{~h}$ after cyclophosphamide. Blood cultures were obtained by plating $100 \mu l$ of blood directly on MacConkey's media (BBL Microbiology Systems, Cockeysville, MD). Plates were then incubated at $37^{\circ} \mathrm{C}$ for $48 \mathrm{~h}$ and examined for visible growth of bacterial colonies. Animals were examined daily, and necropsy examinations were performed within $24 \mathrm{~h}$ after death. All surviving animals were sacrificed at the end of the experiment and underwent necropsy examination as well.

Monoclonal antibody treatment. A hamster-derived anti-murine TNF-alpha monoclonal antibody (TN3 19.12) was provided by $R$. Schreiber, Washington University, St. Louis, MO. This IgG MAb neutralizes natural rat tumor necrosis factor-alpha in an L929 cytotoxicity assay at a level of $19 \mathrm{ng} / \mathrm{U}$ TNF (19). The anti-TNF MAb was given intravenously via tail vein at a dose of $20 \mathrm{mg} / \mathrm{kg}$ at time 0 and $120 \mathrm{~h}$.

A serotype-specific MAb directed against Pseudomonas aeruginosa 12.4.4 (designated MAb 11.14.1) was derived from mouse ascitic fluid as previously described $(17,20)$. This $M A b$ is of the $\operatorname{IgG}_{1}$ isotype and was given intravenously at a dose of $2.5 \mathrm{mg} / \mathrm{kg}$ at time 0 and $120 \mathrm{~h}$. The antibody has previously been shown to possess serotype-specific opsonophagocytic activity and to protect rodents from lethal challenge with $P$. aeruginosa 12.4.4 (20). To determine if MAb 11.14.1 possessed antiendotoxin activity, SDS-PAGE of $P$. aeruginosa LPS immunotypes 1-7 and Western blots were performed as previously described (20). Limulus lysate reactivity by the turbidometric method (Associates of Cape Cod, Woods Hole, MA) was used to compare endotoxin activity of $P$. aeruginosa 12.4.4 LPS before and after the addition of MAb 11.14.1.

A control MAb was also utilized in these experiments as an irrelevant MAb. This MAb was designated L2 3D9 and was given at a dose of $20 \mathrm{mg} / \mathrm{kg}$ intravenously. The monoclonal antibodies used in these experiments were endotoxin free $(<0.05 \mu \mathrm{g} / \mathrm{mg}$ of protein), as determined by Limulus lysate turbidometric assay. The L2 3D9 MAb was hamster derived and was directed against recombinant murine interleukin 2. It does not react with natural mouse or rat interleukin 2 . This monoclonal antibody was prepared in a similar fashion to that of TN3 19.12, the anti-TNF monoclonal antibody.

Blood determinations and necropsy studies. Serum TNF levels were measured using the L929 fibroblast cytotoxicity assay 24 hours before the first dose of cyclophosphamide and $120 \mathrm{~h}$ later. The serum determinations at $120 \mathrm{~h}$ were obtained just before the MAb treatment in each animal. The data are presented in TNF units with one unit indicating the level of TNF required to produce $50 \%$ cytotoxicity of the L929 cells. One unit equals $\sim 22 \mathrm{pg} / \mathrm{ml}$ of TNF in this assay system (21).

Serum levels of anti-TNF monoclonal antibody levels $4 \mathrm{~h}$ after an intravenous administration of $20 \mathrm{mg} / \mathrm{kg}$ of TN3 $19.12(n=4)$ were determined by a direct ELISA system using a peroxidase-labeled goat anti-hamster IgG antibody (19). Serum levels of the anti-LPS monoclonal antibody 11.14.1 $(n=4)$ were measured with an ELISA system with outer membrane complex as the antigen as previously described (17).

At necropsy, all animals had tissue cultures performed of lung heart, spleen, liver, and cecum. Nonlactose fermenting, oxidase-positive colonies which appeared on MacConkey's agar were further identified by agglutination reactions with a polyvalent Pseudomonas aeruginosa antisera set (Difco, Detroit, MI). The challenge strain of Pseudomonas aeruginosa 12.4.4 belongs to Fisher-Devlin-Gnabasik immunotype 6 (17).

Histologic sections of lung, cecum, and kidney tissue were obtained from five lethally infected control animals (group 1) as well as five animals which survived the experiment (group 4).
Data analysis. Four groups of animals were studied in this experiment: group 1, control animals receiving the irrelevant monclonal antibody $\mathrm{L} 2$ 3D9 $(n=16)$; group 2 , animals receiving anti-TNF monoclonal antibody in addition to the irrelevant monoclonal antibody L2 3D9 $(n=16)$; group 3, animals receiving anti-LPS MAb in addition to L2 3D9 $(n=16)$; group 4, animals receiving both anti-TNF as well as anti-LPS MAbs $(n=16)$. As an additional control, 16 other animals received intravenous saline $(0.5 \mathrm{ml})$ instead of any of the MAb preparations. Differences in survival between the four groups were analyzed by Kaplan-Meier survival analysis and generalized Wilcoxon test or Wilcoxon's rank-sum test where appropriate. The differences in serum TNF levels were measured using a Kruskal-Wallis one-way analysis of variance or two-sample $t$ test where appropriate. All analyses were twotailed and $P$ values $<0.05$ were considered significant. Results are expressed as mean $\pm \mathrm{SE}$

\section{Results}

Outcome of treated animals. Animals treated with the irrelevant monoclonal antibody (group 1) experienced a $100 \%$ mortality rate with $0 / 16$ animals surviving the $11-\mathrm{d}$ period after cyclophosphamide administration and oral challenge with Pseudomonas aeruginosa 12.4.4 (Fig. 1). Animals which received saline alone $(n=16)$ also had a $100 \%$ mortality rate (data not shown). Animals treated with anti-TNF MAb alone (group 2) showed a survival rate of $44 \%$ providing a significant survival advantage over group 1 animals $(P<0.02)$. Animals receiving anti-LPS MAb (group 3) exhibited a $37 \%$ survival rate, which was also significantly greater than group 1 animals $(P<0.05)$. Group 4 animals, which received anti-LPS as well as anti-TNF MAb had a $75 \%$ survival rate $(12 / 16)$. Group 4 animals were protected from lethality at a much greater level than group 1 animals $(P<0.0003)$ or either MAb given alone $(P<0.05)$ (Fig. 1).

All animals were found to be severely neutropenic with absolute granulocyte counts of $<100$ granulocytes per microliter by $120 \mathrm{~h}$. Blood cultures obtained $24 \mathrm{~h}$ before the first dose of cyclophosphamide revealed no positive blood cultures for $P$. aeruginosa. Random blood cultures obtained at 72 and $120 \mathrm{~h}$ after cyclophosphamide demonstrated no significant differences in the frequency of Pseudomonas bacteremia between each group: group $1,36 \%$; group $2,42 \%$; group $3,36 \%$; group 4 , $38 \%(P=N S)$. Nonetheless, groups receiving anti-LPS MAb (groups 3 and 4) had a significantly lower quantitative level of bacteremia than groups 1 and $2(59 \pm 21$ vs. $500 \pm 104 \mathrm{cfu} / \mathrm{ml} ; P$ $<0.0001$ ). Anti-TNF MAb treatment did not reduce the frequency or level of bacteremia compared to the control group ( $463 \pm 152$ vs. $543 \pm 149 \mathrm{cfu} / \mathrm{ml} ; P=\mathrm{NS}$ ).

Serum determinations and monoclonal antibody studies. Mean anti-TNF MAb levels in pooled sera measured $4 \mathrm{~h}$ after intravenous administration of TN3 19.12 was $398 \pm 69 \mu \mathrm{g} / \mathrm{ml}$, whereas anti-LPS MAb levels in these same sera were measured at $508 \pm 41 \mathrm{ng} / \mathrm{ml}$. Serum TNF levels were undetectable $24 \mathrm{~h}$ before initiation of the experiment in all animals. Serum TNF levels remained low in both groups of animals which received the anti-TNF MAb: group 2, $0.9 \pm 0.8 \mathrm{U}$; group 4, $0.9 \pm 1.0 \mathrm{U}$. In contrast, control animals (group 1) had markedly elevated levels of TNF at $18.9 \pm 3.4 \mathrm{U}$ at $120 \mathrm{~h}$. Similarly, group 3 animals receiving anti-LPS MAb alone also had elevated serum TNF levels at $21.3 \pm 3.3 \mathrm{U}$. Serum TNF levels were highly significantly different in animals which did not receive anti-TNF MAb (groups 1 and 3) when compared with animals that did receive anti-TNF MAb (groups 2 and 4$)(P<0.0001$ ). 


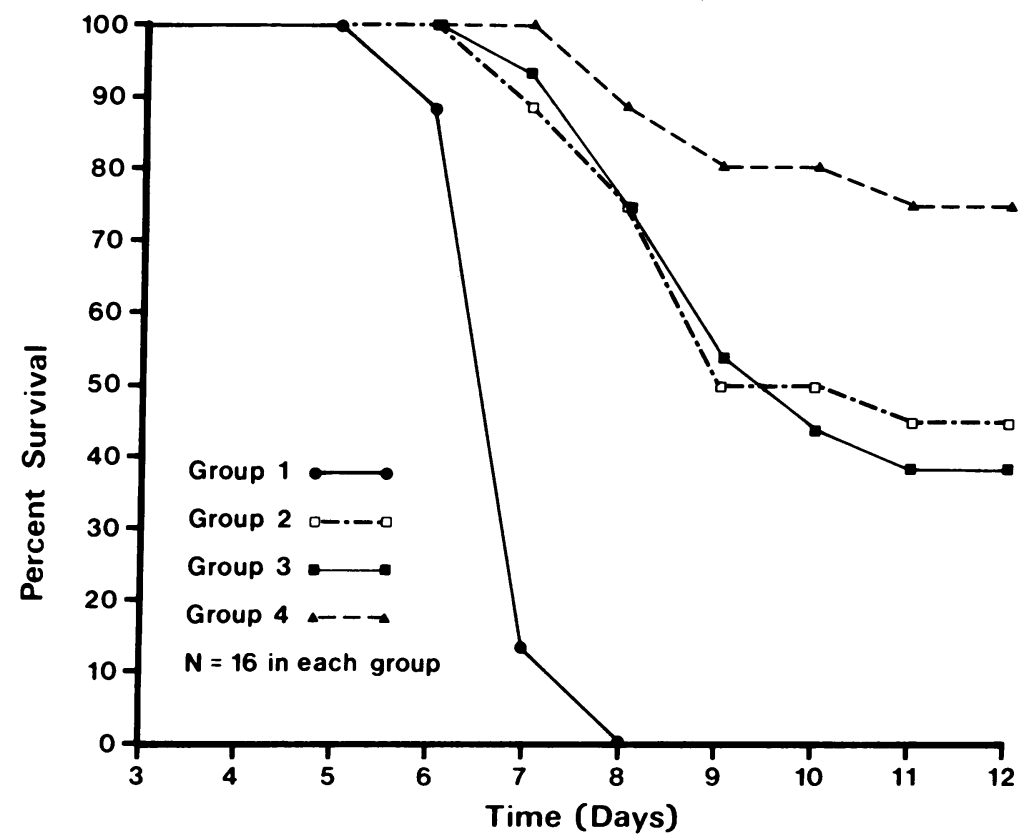

Figure 1. Percent of survival of neutropenic animals after oral challenge with Pseudomonas aeruginosa 12.4.4. Group 1, irrelevant to MAb; group 2, anti-TNF MAb; group 3, anti-LPS MAb; group 4, anti-TNF and anti-LPS MAb.
There was no significant difference in the mean TNF levels in animals receiving the irrelevant MAb when compared with the LPS MAb alone (Fig. 2). Serum TNF levels were significantly higher in group 3 animals which did not survive the duration of the experiment when compared with the six animals in group 3 which survived the duration of the experiment ( $26.0 \pm 3.1$ vs. $10.3 \pm 5.6 \mathrm{U}, P<0.05$ by the two-sample $t$ test). Moreover, serum TNF levels were elevated in nonsurviving animals when compared with survivors who received anti-TNF MAb (groups 2 and 4); but these differences did not reach statistical significance $(3.7 \pm 4.6$ vs. $0.6 \pm 0.7 \mathrm{U}, P=0.07)$.

Analysis of the anti-LPS MAb 11.14.1 demonstrated specific binding of $P$. aeruginosa 12.4.4 LPS only. The Western blot revealed no binding of MAb 11.14.1 to other LPS immunotypes. Limulus reactivity was not altered by the addition of the MAb to $P$. aeruginosa 12.4.4 LPS, indicating that the MAb lacks significant endotoxin-neutralizing effects (data not shown).

Pathologic findings. Necropsy examination of animals which did not survive the period of neutropenia revealed that 93\% had evidence of multisystem infection with the infecting strain of $P$. aeruginosa 12.4.4. One animal in group 1 died of apparent gastrointestinal hemorrhage and another animal in group 3 had pulmonary hemorrhage. Animals which survived the period of neutropenia (5-7 d) were sacrificed at the end of the experiment ( $12 \mathrm{~d}$ after cyclophosphamide). All bacterial cultures of necropsy material were negative with the exception of cecal cultures which remained positive in $30 \%$ of surviving animals. Histologic examination of nonsurviving animals revealed uniform evidence of acute tubular necrosis of renal tissue, mild pulmonary congestion, and interstitial edema in lung tissue and cecal specimens (Fig. 3). Histologic examination of surviving animals revealed no significant pathologic change in lung, cecal, or renal tissues.

\section{Discussion}

There is a sequence of steps through which a potential pathogen that colonizes a mucosal surface must pass before it in- duces septic shock (Fig. 4). Immunotherapeutic intervention might be feasible at each stage. A potential pathogen, such as Pseudomonas aeruginosa, can either invade host tissue and gain entry into the vascular compartment, or, as in the case of infected burn wound eschars, endotoxin itself may gain entry into the bloodstream. In the former case, the organism in the blood may encounter complement, complement and antibody, or complement, antibody, and phagocytes. The bacteria can either evade this encounter until they are ingested by phagocytes in the reticuloendothelial system, or they may be lysed, which may result in the release of endotoxin into the circulation. When either the nonbacterially associated LPS or the intact organism encounters the macrophage, cytokines are generated which are believed to be a final common pathway in the development of the septic state.

It may be possible to intervene at each step in this process. Strategies have been devised to block the initial colonization step by inhibiting either the adhesions on the bacteria or by

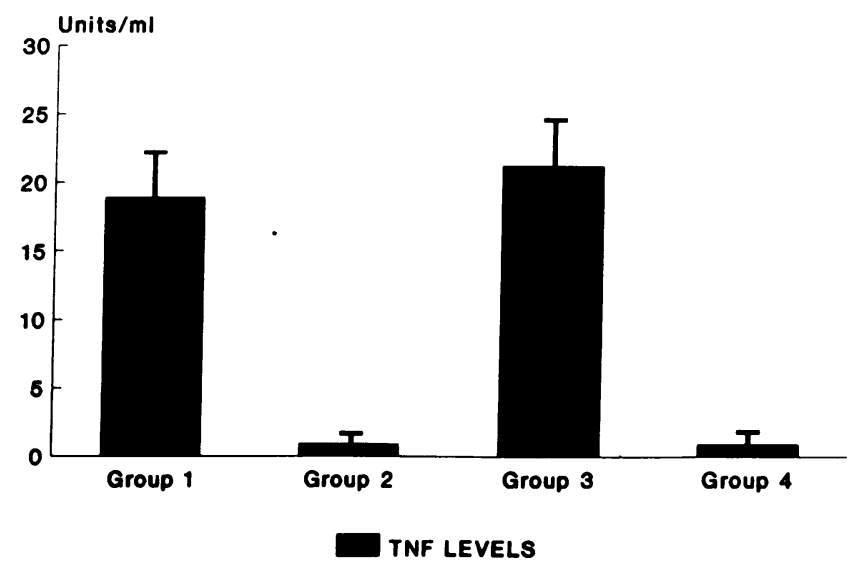

Figure 2. Serum TNF levels $120 \mathrm{~h}$ after the first oral challenge of $P$. aeruginosa 12.4.4. The results are expressed as mean endotoxin units \pm SEM. Group 1, irrelevant MAb; group 2, anti-TNF MAb; group 3, anti-LPS MAb; group 4, anti-TNF and anti-LPS MAb. 



Figure 3. Pathologic findings in septic animals from group 1. (A) Lung tissue showing vascular congestion and interstitial edema. (B) Renal tissue showing evidence of acute tubular necrosis. 


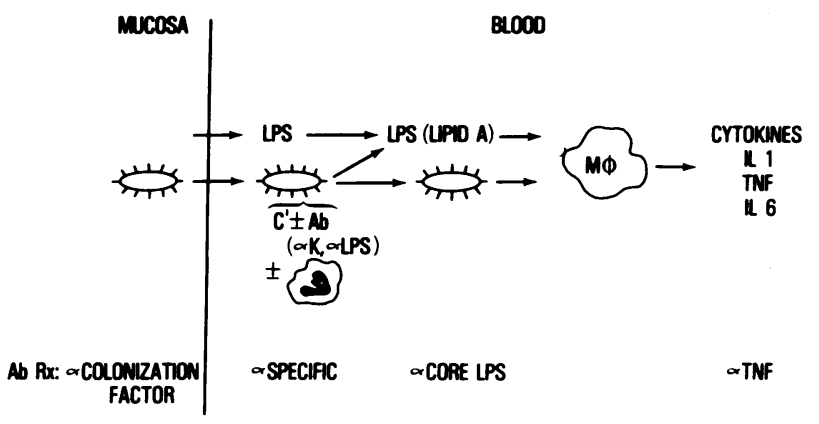

Figure 4. Potential sites of action of immunotherapy against gram-negative bacterial infection. Antibodies may be useful at prevention of colonization; opsonizing and promoting complement activation by specific binding to surface structures of bacteria (LPS, K capsules); detoxifying LPS by binding to core glycolipid; or blocking the pathologic effects caused by the release of cytokines (TNF, IL-1, IL-6). Ab Rx, antibody therapy; $\alpha$, anti; C, complement.

blocking the putative receptors on the cell surface of the exposed tissue. At a next phase, the provision of pharmacologic amounts of bacteria-specific antibody (directed at a cell surface structure such as the capsule or LPS) may enhance the lysis or clearance of bacteria. In a further step, antibody directed at common core epitopes in the LPS may neutralize the ability of LPS, either free in the circulation after immunologic or antimicrobial-induced lysis, or on intact bacteria, to initiate its cascade of biologic effects. Should the LPS or bacterium encounter a macrophage, however, an analogue of the active lipid A moiety of LPS, such as lipid X, may block or interfere with the ability of LPS to induce cytokine production by that cell. Finally, should those measures not succeed in preventing stimulation of cytokine production by the macrophages, cytokineneutralizing antibody may provide amelioration of the septic state.

Because each of these separate steps involves a different site or target for immunotherapeutic attack, one might expect that the administration of antibodies that function at separate sites, may provide synergistic or at least additive effects, in a manner not unlike the sequential effects of trimethoprim-sulfamethoxazole on the folic acid metabolic pathway of bacteria. This concept was tested in this study. In the absence of antimicrobial therapy, a monoclonal antibody directed at the LPS O-side chain that mediates opsonophagocytosis, or another monoclonal antibody that neutralizes the biological effects of tumor necrosis factor each afforded significant protection from lethal Pseudomonas bacteremia. When given together, however, there was a significantly enhanced survival.

We are currently assessing whether the addition of a third antibody, directed at a core glycolipid determinant that may be important for the biological effects of LPS, might provide even greater protection against Pseudomonas sepsis. Should this approach result in maximally enhanced protection, then the concept of a "cocktail" of monoclonal antibodies, each designed to overcome activation of sequential stages of the septic process in combination with antimicrobial agents, may become the optimal treatment for septic shock.

Antibodies directed against TNF- $\alpha$ offer a novel immunotherapeutic approach in the management of septic shock. The results of the current study indicate that anti-TNF MAb alone, even in the absence of antimicrobial agents, will partially pro- tect animals from otherwise lethal $P$. aeruginosa infection during a period of chemotherapy-induced neutropenia. These findings demonstrate that an anti-TNF MAb not only protects animals in toxicity models (11-14) but also in an actual infection model $(15,18)$. The neutropenic rat model more closely mimics a clinical infection in that endogenously mediated bacteremia occurs after alimentary tract colonization with an opportunistic gram-negative bacillus such as Pseudomonas aeruginosa (17). The protective efficacy of polyclonal and monoclonal antibody directed against TNF has been amply demonstrated in a variety of endotoxic models in experimental animals (11-14). The neutropenic rat model offers an opportunity to study the value of this immunotherapeutic approach against a virulent, replicating bacterial infection in an immunocompromised animal $(17,18)$.

TNF- $\alpha$ is known to duplicate most of the metabolic and pathophysiologic effects of endotoxin in animal models (11, 22-24). Serum TNF levels have been found to be abruptly elevated in endotoxic challenge in human subjects (25) as well as in patients with meningococcemia and infectious purpura $(26,27)$. The level of circulating TNF was found to be a prognostic indicator in some human infections, with elevated TNF levels indicating a greater severity of illness (28) and a worse prognosis (26). Nonsurviving animals receiving an anti-LPS $\mathrm{MAb}$ in the current study also demonstrated higher levels of serum TNF compared with surviving animals.

Serotype-specific anti-LPS MAb offers partial protection in this animal model against the infecting strain of Pseudomonas aeruginosa 12.4.4 given intraperitoneally (17), or intravenously, as in the current study. This antibody has been shown to be bacteriocidal in the presence of phagocytes (20) and promotes clearance of bacteremia even in severely neutropenic animals (17). Whereas MAb 11.14.1 failed to reduce the frequency of bacteremia in the current study, the antibody did result in a diminished quantitative level of bacteremia from the infecting strain of $P$. aeruginosa. The antibody may facilitate the clearance of $P$. aeruginosa 12.4 .4. by tissue phagocytic cells which continue to function during the neutropenic period.

Despite the partial protection availed by anti-LPS MAb, serum TNF levels were not significantly reduced compared to group 1 control animals. This suggests that the protection afforded by an anti-LPS MAb may not be solely mediated by reduction in serum TNF levels. Similar observations have recently been reported by others $(29,30)$. Anti-LPS antibodies would be expected to have a variety of salutary effects despite continued cytokine production. Such antibodies may limit complement activation, endorphin production, or the clotting cascade which would be of benefit to the host during systemic infection (30). This would also indicate that a combination of anti-LPS and anti-TNF monoclonal antibodies might be expected to have additive or synergistic effects in the prevention of lethal septic shock. The potential utility of an anti-core glycolipid MAb has yet to be determined in this experimental model of Pseudomonas sepsis. Anti-core glycolipid MAb would be expected to provide broad protection against a variety of infecting strains of Pseudomonas aeruginosa as well as gram-negative enteric bacteria. The potential efficacy of anti-core glycolipid MAb has recently been reported in two human trials $(31,32)$.

The combination of an anti-LPS and anti-TNF MAb demonstrated additive protective efficacy in this neutropenic rat model of lethal Pseudomonas sepsis. Whether similar results 
will be obtained using a core glycolipid monoclonal antibody in lieu of a serotype-specific anti-LPS MAb remains to be determined. Certainly this approach of a combination of monoclonal antibodies would provide an attractive therapeutic strategy in the management of patients with serious infections with gram-negative bacilli in the presence of neutropenia or other predisposing conditions. The combination of antibodies directed against LPS and TNF- $\alpha$ in addition to standard antimicrobial agents may be the most efficacious therapeutic approach available at the present time. Further studies will be necessary to determine the most appropriate timing and dose of monoclonal antibodies in septic shock state and the potential utility of this approach in the management of a variety of other strains of Pseudomonas aeruginosa as well as enteric gram-negative bacilli.

\section{Acknowledgments}

The authors would like to thank Dr. M. Nicknian for the statistical analysis and G. Armstrong for preparing the manuscript.

This work was supported in part by a grant from Celltech Ltd., Slough, UK, and The Rhode Island Foundation grant No. 88339.

\section{References}

1. Pizzo, P. A., and L. S. Young. 1984. Limitations of current antimicrobial therapy in the immunosuppressed host: looking at both sides of the coin. Am. J. Med. 76:S101-S107.

2. Young, L. S. 1990. Gram-negative sepsis. In Principles and Practice of Infectious Diseases. G. L. Mandell, R. G. Douglas, and J. E. Bennett, editors. Churchill-Livingstone, Inc., New York. 611-636.

3. van Dijk, W. C., H. A. Verbrugh, M. E. van Erne-van der Tol, R. Peters, and J. Verhoef. 1981. Escherichia coli antibodies in opsonization and protection against infection. J. Med. Microbiol. 14:381-389.

4. Schellekens, J., E. Brouwer, T. Calandra, M. Rozenberg-Arska, and J. Verhoef. 1989. Humoral immunity in human gram-negative septic shock. II. Specific anti-bacterial immunity: opsonic activity and the effect of intravenous immunoglobulin G administration. Serodiagnosis Immunother. Infect. Dis. 3:279-291.

5. Shenep, J. L., P. M. Flynn, F. F. Barrett, G. L. Stidham, and D. F. Westenkirchner. 1988. Serial quantitation of endotoxemia and bacteremia during therapy for gram-negative bacterial sepsis. J. Infect. Dis. 157:565-568.

6. Ziegler, E. J. 1988. Protective antibody to endotoxin core: the emperor's new clothes? J. Infect. Dis. 158:286-290.

7. Ziegler, E. J., J. A. McCutchan, J. Fierer, M. P. Glauser, J. C. Sadoff, H Douglas, and A. I. Braude. 1982. Treatment of gram-negative bacteremia and shock with human anti-serum to a mutant Escherichia coli. N. Engl. J. Med. 307:1225-1230.

8. Teng N. N. H., H. S. Kaplan, J. M. Hebert, C. Moore, H. Douglas, A Wonderlich, and A. I. Braude. 1985. Protection against gram-negative bacteremia and endotoxemia with human monoclonal IgM antibodies. Proc. Natl. Acad. Sci. USA. 82:1790-1794.

9. Beutler, B., and A. Cerami. 1986. Cachectin and tumor necrosis factor as two sides of the same biological coin. Nature (Lond.). 320:584-588.

10. Beutler, B., and A. Cerami. 1987. Cachectin: more than a tumor necrosis factor. N. Engl. J. Med. 316:379-385.

11. Beutler, B., I. W. Milsark, and A. C. Cerami. 1985. Passive immunization against cachectin/tumor necrosis factor protects mice from lethal effects of endotoxin. Science (Wash. DC). 229:869-871.

12. Mathison, J. C., E. Wolfson, and R. C. Ulevitch. 1988. Participation of tumor necrosis factor in the mediation of gram-negative bacterial lipopolysaccharide-induced injury in rabbits. J. Clin. Invest. 81:1925-1937.

13. Tracey, K. J., B. Beutler, S. F. Lowry, J. Merriweather, S. Wolpe, I. W. Milsark, R. J. Hariri, T. J. Fahui, A. Zentella, J. D. Albert, G. T. Shires, and A. Cerami. 1986. Shock and tissue injury induced by recombinant human cachectin. Science (Wash. DC). 234:470-473.

14. Silva, A. T., K. F. Bayston, and J. Cohen. 1990. Prophylactic and therapeu- tic effects of a monoclonal antibody to tumor necrosis factor- $\alpha$ in experimental gram-negative shock. J. Infect. Dis. 162:421-427.

15. Tracey, K. J., Y. Fong, D. G. Sesse, K. R. Monogue, A. T. Lee, G. C. Cou, S. F. Lowry, and A. Cerami. 1987. Anti-cachectin/TNF monoclonal antibodies prevent septic shock during lethal bacteremia. Nature (Lond.). 330:662-664.

16. Exley, A. R., J. Cohen, W. Buurman, R. Owen, G. Hanson, J. Lumley, J. M. Aulakh, M. Bodmer, A. Riddell, S. Stephens, and M. Perry. 1990. Murine monoclonal antibody to recombinant human tumor necrosis factor in the treatment of severe septic shock. Lancet. 335:1275-1276.

17. Collins, H. H., A. S. Cross, A. Dobeck, S. M. Opal, J. B. McClain, and J. C. Sadoff. 1989. Oral ciprofloxacin and a monoclonal antibody to lipopolysaccharide protect leukopenic rats from lethal infection with Pseudomonas aeruginosa. J. Infect. Dis. 159:1073-1082.

18. Opal, S. M., A. S. Cross, N. M. Kelly, M. W. Bodmer, J. E. Palardy, and G. H. Victor. 1990. The efficacy of a monoclonal antibody directed against tumor necrosis factor in protecting neutropenic rats from lethal infection with Pseudomonas aeruginosa. J. Infect. Dis. 161:1148-1152.

19. Sheehan, K. C. F., N. H. Ruddle, and R. D. Schreiber. 1989. Generation and characterization of hamster monoclonal antibodies which neutralize murine tumor necrosis factors. J. Immunol. 142:3884-3893.

20. Sadoff, J. C., D. C. Wright, S. Futrovsky, H. Sidberry, H. Collins, and B. Kaufmann. 1985. Characterization of mouse monoclonal antibodies directed against Pseudomonas aeruginosa lipopolysaccharides. Antibiot. Chemother. 36:134-146.

21. Cross, A. S., J. C. Sadoff, N. M. Kelly, A. Burnton, and P. Gemski. 1989. Pre-treatment with recombinant murine tumor necrosis factor $\alpha /$ cachectin and murine interleukin $1 \alpha$ protects mice from lethal bacterial infection. J. Exp. Med. 169:2021-2027.

22. Tracey, K. J., S. F. Lowry, T. J. Fahley, J. D. Albert, Y. Fong, D. Hesse, B. Beutler, K. R. Manogue, S. Calvano, H. Wei, A. Cerami, and G. T. Shires. 1987 Cachectin/tumor necrosis factor induces lethal shock and stress hormone responses in the dog. Surg. Gynecol. \& Obstet. 164:415-422.

23. Mannel, D. N., H. Northoff, F. Bauss, and W. Falk. 1987. Tumor necrosis factor: a cytokine involved and toxic effects of endotoxin. Rev. Infect. Dis. 9:S602-S606.

24. Hesse, D. G., K. J. Tracey, W. Fong, K. R. Manogue, M. A. Palladino, Jr., A. Cerami, G. T. Shires, and S. F. Lowry. 1988. Cytokine appearance of human endotoxemia and primate bacteremia. Surg. Gynecol. Obstet. 166:147-153.

25. Michie, H. R., K. R. Manogue, D. R. Spriggs, A. Revhaug, S. O'Dwyer, C. A. Dinarello, A. Cerami, S. M. Wolff, and D. W. Wilmore. 1988. Detection of circulating tumor necrosis factor after endotoxin administration. N. Engl. J. Med. 318:1481-1486.

26. Waage, A., A. Halstensen, and T. Espevik. 1987. Association between tumor necrosis factor in serum and total outcome in patients with meningococcal disease. Lancet. i:355-357.

27. Girardin, E., G. E. Grau, J.-M. Dayer, P. Roux-Lombard, J-5 Study Group, and P.-H. Lambert. 1988. Tumor necrosis factor and interleukin-1 in the serum of children with severe infectious purpura. N. Engl. J. Med. 319:397-400.

28. Cannon, J. G., R. G. Tompkins, J. A. Gelfand, H. R. Michie, G. G. Stanford, J. W. M. van der Meer, S. Endres, G. Lonnemann, J. Corsetti, B. Chernow, D. W. Wilmore, S. M. Wolff, J. F. Burker, and C. A. Dinarello. 1990 Circulating interleukin-1 and tumor necrosis factor in septic shock and experimental endotoxin fever. J. Infect. Dis. 161:79-84.

29. Chia, J. K. S., M. Pollack, G. Guelde, N. L. Koles, M. Miller, and M. E. Evans. 1989. Lipopolysaccharide (LPS)-reactive monoclonal antibodies fail to inhibit LPS-induced tumor necrosis factor secretion by mouse-derived macrophages. J. Infect. Dis. 159:872-880.

30. Silva, A. T., B. J. Applemelk, W. A. Buurman, K. F. Bayston, and J. Cohen. 1990. Monoclonal antibody to endotoxin core protects mice from Escherichia coli by a mechanism independent of tumor necrosis factor and interleukin 6. J. Infect. Dis. 162:454-459.

31. Gorelick, K., R. Jacobs, H. Chmel, G. Trenholme, R. Greenman, and Xoma Sepsis Study Group. 1989. Efficacy results of a randomized multicenter trial of E5 antiendotoxin monoclonal antibody in patients with suspected gramnegative sepsis. The 29th Interscience Conference on Antimicrobial Agents and Chemotherapy. 18 September 1989, Houston TX. (Abstr. No. 2.)

32. Zeigler, E. J., C. J. Fisher, Jr., C. L. Sprung, R. C. Straube, J. C. Sadoff, G. E. Foulke, C. H. Wortel, M. P. Fink, R. P. Dellinger, N. N. H. Teng, I. E. Allen, H. J. Berger, G. L. Knatterud, A. F. LoBuglio, C. R. Smith, and HA-1A Sepsis Study Group. 1991. Treatment of gram-negative bacteremia and septic shock with HA-1A human monoclonal antibody against endotoxin. $N$. Engl. $J$. Med. 324:429-436. 